\title{
Menjadi Islam Nusantara yang Unggul (Studi atas Kitab al- Minhah al-Khairiyah Karya Mahfuzh at-Tarmasi)
}

\author{
Rimanur Sakdiyah dan Ria Candra Widayaningsih \\ Institut Agama Islam Negeri (IAIN) Salatiga \\ rimanursakdiyah34@gmail.com
}

\begin{abstract}
This paper introduces the work of Mahfuzh at-Tarmasi (d. 1920 M) in the field of hadith, entitled al-Minhah al-Khairiyah fi Arba'in Haditsan min Ahaditsu Khair alBariyah, known as Arba'in at-Tarmasi. This book contains 40 hadiths written musalsal (genealogically) originating from Kutub al-Sittah and Tsulatsiyat al-Bukhari. This is based on the hadith practice on the virtue of gathering 40 hadiths of Nabawi. Interestingly, the main themes carried by this book focused on four things: aqidah (theology), ubudiyah (worship), mu'amalah (social relations) and siyasah (political strategies). These four things are important pillars in the reality of the life of Nusantara Muslim communities, considering that the period in Indonesia was experiencing colonialism by Dutch imperialism. At-Tarmasi (d. 1920 M) reminded of the importance of studying the pillars directly from the source.
\end{abstract}

Keywords: Hadith, Arba'in at-Tarmasi, Indonesian Muslim.

\begin{abstract}
Abstrak
Tulisan ini mengenalkan karya Mahfuzh at-Tarmasi (w. 1920 M) di bidang hadis, berjudul al-Minhah al-Khairiyah fi Arba'in Haditsan min Ahaditsu Khair al-Bariyah, dikenal Arba'in at-Tarmasi. Kitab ini berisi 40 hadis nabawi yang ditulis secara musalsal yang bersumber dari Kutub al-Sittah dan Tsulatsiyat al-Bukhari. Hal ini dilandasi atas pengamalan hadis tentang keutamaan bagi pengumpul 40 hadis nabawi. Menariknya, tema-tema pokok yang diusung kitab ini terfokus pada empat hal: aqidah (teologi), ubudiyah (peribadatan), mu'amalah (relasi sosial) dan siyasah (startegi politik). Keempat hal inilah yang menjadi pilar-pilar penting dalam realitas kehidupan masyarakat Muslim di Nusantara, mengingat masa itu di Indonesia sedang mengalami penjajahan oleh imperialisme Belanda. AtTarmasi (w. 1920 M) mengingatkan akan pentingnya mengkaji pilar-pilar tersebut langsung dari sumbernya.
\end{abstract}

Kata Kunci: Hadith, Arba'in at-Tarmasi, Indonesian Muslim. 
Millatī, Journal of Islamic Studies and Humanities, Vol. 3, No. 2, Des. 2018: 261-275

\section{Pendahuluan}

Kajian hadis di Indonesia ditengarai telah berlangsung sejak awal masuknya Islam ke wilayah ini. Aktvitas tersebut terus berlanjut dan semakin meningkat hingga paruh kedua abad ke-17 seiring dengan masuknya gagasan pembaharuan yang menekankan al-Qur'an dan al-Hadis kembali sebagai sumber ajaran dan membendung masuknya tradisi lokal ke dalam Islam. ${ }^{1}$ Meskipun demikian, sampai awal abad ke-20, kajian hadis secara khusus kurang populer. Ini dikarenakan, menurut Howard M. Federspiel, kajian hadis pada masa penjajahan Belanda masih menjadi bagian dari kajian fiqh, bukan kajian tersendiri. ${ }^{2}$ Maka lebih sering menjumpai kitab-kitab fikih dan tasawwuf yang ditulis ulama, bahkan lebih banyak dari disiplin manapun. Meskipun demikian, bukan berarti tidak ada sama sekali tokoh-tokoh yang mengarah ke studi Hadis, meski hanya sedikit jumlahnya.

Perkembangan kajian Hadis di Indonesia sangat pesat setelah dipelopori oleh Mahfuzh at-Tarmasi (w. 1920 M), dikenal at-Tarmasi. Olehnya, Hadis berdiri sendiri dan dijadikan sebagai kurikulum pesantren. Selanjutnya diteruskan oleh muridnya, Hasyim Asy'ari (w. 1947 M) dengan pondok Hadisnya di Tebuireng, Jombang, Jawa Timur. At-Tarmasi (w. 1920 M) adalah pribadi yang prolifik. Banyak karya yang dihasilkan dari ketekunan belajarnya. Karangannya mencapai lebih dari 20 kitab dan seluruhnya ditulis dalam bahasa Arab. Beliau dikenal sebagai ahli Hadis dan Ulum Al-Hadis, sehingga melalui karya-karyanya ia dijuluki sebagai 'Imam al-Bukhari abad 19'. ${ }^{3}$ Karya-karya beliau belum begitu banyak dikaji di beberapa pesantren Nusantara, namun karyanya justru dipakai di beberapa perguruan tinggi di Timur Tengah, seperti di Marokko, Arab Saudi, Iraq dan beberapa negara lainnya.

${ }^{1}$ Salah satu bukti adanya kajian hadis di masa lalu adalah sebuah kitab berjudul alFawa'id al-Bahiyah fi al-Ahadis al-Nabawiyah karangan Nuruddin Ar-Raniry (w. 1658 M), yang merupakan kitab hadis Melayu pertama. Sayangnya, kitab yang memuat 831 buah hadis shahih itu tidak satu pun dijumpai di perpustakaan-perpustakaan negeri ini. Hanya ada satu di PNM Kuala Lumpur, tercatat dengan kode MS 1042. Padahal kitab ini merupakan salah satu sumber primer pertama di bidang hadis dalam konteks sejarah Islam Melayu. Oman Fathurrahman, "Ulah Malaysia dan Ketidakpedulian Kita", Agung, Danarto. Kajian Hadis di Indonesia Tahun 1900-1945 (Telaah terhadap Pemikiran Beberapa Ulama tentang Hadis) (Yogyakarta: Proyek Perguruan Tinggi Agama Islam, IAIN Sunan Kalijaga, 2000), h. 8

${ }^{2}$ Muh. Tasrif, dkk. "Rekontekstualisasi Al-Hadits di Indonesia", dalam Jurnal Istiqra, volume 03, nomor 01, 2004, h. 271-272

3 ibid, h. 163 
Karya at-Tarmasi (w. 1920 M) yang berjudul al-Minhah al-Khairiyah fi Arba in Haditsan min Ahāaditsu Khair al-Bariyah dalam bidang Hadis, menarik untuk dikaji, mengingat begitu kuatnya pengaruh beliau di masyarakat dan juga pengaruh Hadis sendiri di masyarakat. Di samping itu, dalam penyusunan bab-bab yang terdapat dalam kitab tersebut pun berbeda dengan kitab-kitab hadis yang telah ada sebelumnya. Jika dalam kitab-kitab hadis pada umumnya disusun berdasarkan urutan bab-bab fiqih, kitab ini justru di awali dengan hadis tentah saling mengasihi (rahmah). Dalam konteks masyarakat Nusantara, kitab ini mengindikasikan adanya ajaran-ajaran moderat yang sejak lama ditanamkan oleh at-Tarmasi (w. 1920 M).

\section{Mengenal Mahfuzh at-Tarmasi (w. 1920 M) dan Karya-Karyanya}

Nama lengkap ulama hadis nusantara itu adalah Muhammad Mahfldz Ibn 'Abdullah Ibn Abdul Manan at-Tarmasi. ${ }^{4}$ At-Tarmasi lahir pada 31 Agustus 1868 bertepatan pada 12 Jumadil Awal 1285 H, di daerah Tremas, Arjosari, Pacitan, Jawa Timur. ${ }^{5}$ Ia adalah putra dari Kyai Abdullah, seorang pemimpin Pesantren di Termas yang sangat terkenal sejak pertengahan abad $19 .{ }^{6}$ Di dalam karyanya al-Khil'ah al-Fikriyyah Syarh al-Mihnah al-Khairiyyah terdapat indikasi tentang penyebutan nisbat yang bisa dibenarkan, yaitu dengan membaca fathah pada huruf ta' dan mim-nya serta mensukunkan huruf ra' sehingga bacaan yang tepat adalah at-Tarmasi.?

Secara historis, masa kecil at-Tarmasi (w. 1920 M) banyak diasuh dan dibesarkan ibu dan pamannya. Sudah barang at-Tarmasi (w. 1920 M) diajarkan segala tradisi keagamaan yang berlaku pada masa itu, khususnya di lingkungan Pesantren Termas. Jadi pemikiran keagamaan at-Tarmasi (w. 1920 M) pada masa kecilnya sangat dipengaruhi keluarga dan lingkungannya, yang kesemuanya bisa dibilang tradisionalis. ${ }^{8}$ Kearifan atau milieu Pesantren, yang hampir setiap harinya

\footnotetext{
${ }^{4}$ Muhajirin, Kebangkitan Hadits Di Nusantara (Yogyakarta: Idea Press, 2016), h. 53

${ }^{5}$ Rizem Aizid, Biografi Ulama Nusantara: Disertai Pemikiran dan Pengaruh Mereka (Yogyakarta: Diva Press, 2016), h. 250

${ }^{6}$ Muhajirin, Muhammad Mahfudz at-Tarmasi (1868-1919): Ulama Hadits Nusantara Pertama (Yogyakarta: Idea Press, 2016), h. 17-18

${ }^{7}$ At-Tarmasi, Al-Khilah al-Fikriyah Syarah al-Mihnah al-Khairiyah (Jakarta, Departemen Agama Republik Indonesia, 2008), h. 4

${ }^{8}$ Tradisionalis adalah paham atau ajaran berdasarkan tradisi yang berasal dari ajaranajaran yang terstruktur sedemikian rupa sehingga menjadi praktik yang hidup dalam masyarakat tertentu. Wacana Intelektualisme Dalam Komunitas NU, Direktorat Jendral Pendidikan Islam,
} 
Millatī, Journal of Islamic Studies and Humanities, Vol. 3, No. 2, Des. 2018: 261-275

menghadirkan suasana keilmuan, tentunya sangat mempengaruhi kepribadian at-Tarmasi (w. 1920 M) atas kecintaannya terhadap ilmu pengetahuan. ${ }^{9}$

At-Tarmasi (w. 1920 M) pada usia 6 tahun atau pada tahun $1291 \mathrm{H}$ dibawa ayahnya ke Makkah untuk pertama kalinya. Setinggalnya di sana, at-Tarmasi (w. 1920 M) dikenalkan ayahnya dengan berbagai kitab penting, tentunya tanpa mengurangi haknya sebagai seorang anak untuk bermain seperti anak-anak pada umumnya. Setelah beberapa tahun menikmati udara Makkah, ia pun ikut kembali ke nusantara bersama ayahnya. ${ }^{10}$ Sepulang dari Makkah, at-Tarmasi (w. 1920 M) menikmati masa kecilnya di lingkungan pondok Pesantren Termas. Melihat semangat yang dimiliki, ayahnya menitipkan at-Tarmasi (w. 1920 M) ke sebuah pesantren asuhan kiyai Shaleh, sebuah pesantren yang dirintis Murtadha di kampung Darat Semarang, sehingga dikenal dengan Pesantren Shaleh Darat. Sepeninggal kiyai Murtadha, kiyai Shaleh Darat (w. 1903 M) ditunjuk menjadi penerus untuk mengelola pesantren Darat. Sejak itu, pesantren semakin maju dan sangat masyhur. Pesantren Darat termasuk pesantren yang besar pada waktu itu, dan sudah memiliki ratusan santri. ${ }^{11}$

Pengaruh kuat Shaleh Darat (w. 1903 M) menginspirasi at-Tarmasi (w. 1920 M) untuk mengikuti jejak gurunya. Setelah tamat dari pesantren Shaleh Darat, yang merupakan lembaga pertama at-Tarmasi dalam mengenyam pendidikan formal, at-Tarmasi melanjutkan studinya ke Haramain, seperti yang pernah ditempuh oleh ayahnya juga gurunya. ${ }^{12}$ Mulailah at-Tarmasi (w. 1920 M) mengadakan rihlah ilmiah ke Haramain untuk kedua kalinya, yakni pada tahun 1308 H. Selama di Makkah beliau mendalami banyak banyak ilmu agama. Tidak hanya hadis yang kemudian menjadi bidangnya, akan tetapi pelbagai disiplin keilmuan ia pelajari dengan berbagai macam bentuk pembelajaran mulai dari halaqah, ribaht -semacam pondokan- dan juga kuttab, yakni berupa madrasah kecil yang diselenggarakan di rumah-rumah pengajar.

Dengan kegigihan, keseriusan dan ketekunannya mempelajari hadis atTarmasi (w. 1920 M) mulai dikenal. Namanya semakin familiar bagi pecinta hadis, qiro'at dan fiqih, baik di dunia akademik dan juga pesantren. ${ }^{13}$ Ia merupakan

Departemen Agama, Jakarta, 2007, h. 11

${ }^{9}$ Secara teori, seorang yang berada di lingkungan komunitas tertentu, akan terpengaruh dengan bentuk dan pola komunitas tersebut, kendati tidak semua sisi mempengaruhinya

${ }^{10}$ Muhajirin, Kebangkitan Hadits ..., h. 57

${ }^{11}$ Ibid, h. 57-58

${ }^{12} \mathrm{Ibid}$, h. $59-60$

${ }^{13}$ Muhajirin, "At-Tarmasi: Icon Baru Ulama Hadits Arba'in Di Indonesia”, Jurnal 
tokoh penting dalam sejarah perjalanan pesantren sekaligus perkembangan ilmu hadis di Indonesia. ${ }^{14}$ Kemasyhuran namanya membawanya menjadi tokoh penting dalam sejarah perjalanan pesantren sekaligus perkembangan ilmu hadis di Indonesia. ${ }^{15}$ Karena itu at-Tarmasi (w. 1920 M) dijuluki sebagai bapak ahli hadis di Indonesia.

At-Tarmasi (w. 1920 M) menjadi ulama hadis Nusantara yang intelektualitasnya tidak perlu diragukan kembali. Sejak awal abad XX telah ditemukan karya-karya at-Tarmasi (w. 1920 M) dalam berbagai disiplin ilmu. Abdurrahmad Wahid (Gusdur) berkomentar bahwa at-Tarmasi (w. 1920 M) merupakan salah satu ulama Nusantara awal abad XX yang produktif dengan karya-karya yang dimilikinya. Di antaranya: Al-siqayah al-mardiyah fi asami kutub ashabina al-syafi'iyah, Al-minhah al-khairiyyah fi arbain haditsan min ahadits khair al-bariyah, Al-khil'ah al-fikriyyah bi syarh al-minhah al-khairiyyah, Muhibah dzi al-fadl hasyiyah syarh al-mukhtashar bi afdhal, Kifayah al-mustafid fima ala min al-asanid, Al-fawaid al-tirmisiyah fi asanid al-qira'at al-asyriyyah, Al-badr al-munir fi kira'at al-imam ibn katsir, Tanwir al-shadr fi qira'at al-imam abi amru, Insyirah al-fuadi fi qiraat al-imam al-hamzah, Ta'mim al-manafi' fi qira'at al-imam nafi, Is'af al-mathali' bi syarh badr al-lami' nazm jam' al-jawami', Ghunyah al-thalabah bi syarh at-tayyibah, Al-asyriyyah, Hasyiyah taklimah al-manhaj al-qawim ila al-faraid, Manhaj dzaw al-nazr bi syarh manzumah 'ilm al-atsar, Nayl al-ma;mul bihashiyah ghayah al-wusul fi 'ilm al-ushl, Inayah al-muftaqir fima yata'allaq bi sayyidina al-hadar, Bughyah al-adzkiya fi al-bahts 'an karamah al-awliyah, Fath al-khabir bi syarh miftah al-sayr, Tahyi'at al-fikr bi syarh alfiyah al-sayr, dan Tsulastiat al-bukhari.

Karya-karya hadis at-Tarmasi di atas banyak yang sudah terindeks dalam mu'jam al-hadis. Hal ini membuktikan bahwa karya beliau sudah disebarluaskan dan dijadikan rujukan para pelajar di luar negeri masa itu. Meskipun begitu, dari pelbagai karya at-Tarmasi tidak semuanya ditemukan manuskripnya. Karya at-Tarmasi tidak semuanya dicetak secara masal sehingga sulit untuk bisa diakses oleh pelbagai pihak. Menurut beberapa referensi, karya-karya at-Tarmasi justru diterbitkan di luar negeri, seperti Mesir, Beirut dan sebagian kecil di Indonesia. Sebagian karyanya, terutama karya di bidang hadis, mendapatkan perhatian khusus oleh Kementrian Agama Republik Indonesia, sehingga diterbitkan dengan menggunakan anggaran dana dari Kemenag.

ASILHA International Conference, h. 313

${ }^{14}$ Ibid, h. 760

${ }^{15} \mathrm{Ibid}, \mathrm{h} .760$ 
Millatī, Journal of Islamic Studies and Humanities, Vol. 3, No. 2, Des. 2018: 261-275

Pada paruh kedua abad XX karya at-Tarmasi (w. 1920 M) sudah banyak dipakai di Indonesia, hanya saja belum diterjamah oleh para penulis, karena tidak semua pesantren mengunakan kitabnya. ${ }^{16}$ Dalam pelbagai penelitian, karya atTarmasi memiliki kontribusi terhadap standar kompetensi Pondok Pesantren yang berasaskan pada: pertama, aktif dalam hal memperdalam dasar-dasar keilmuan baik yang bersifat aqidah, syari'ah maupun akhlak. Kedua, Kreatif dan inovatif dalam mengembangkan dan menggali hukum syari'ah. Ketiga, Kompetitif dalam hal akhlaqul karimah dan ber-mu'amalah dalam masyarakat. Untuk mewujudkan itu, karya-karya At-Tarmasi (w. 1920 M) terfokus pada masalah aqidah yang dapat membentuk kecerdasan spiritual dengan harapan mampu memberikan kontribusi supaya para lulusannya bisa mempunyai kecerdasan spiritualnya. Syari'ah untuk membentuk insan yang aktif dalam hal melaksanakan kegiatan yang bersifat agama, baik yang bersifat mahdhah maupun ghoiru mahdhah tentunya, dan berinovasi dalam mengatasi permasalahan-permasalahan mu'amalah yang semakin berkembang, dengan tanpa keluar dari kaidah-kaidah yang bersumber dari al-Qur'an, Hadis, Ijma', dan Qiyas. ${ }^{17}$

Sepak terjang at-Tarmasi (w. 1920 M) sangat berpengaruh bagi pengkaji hadis di Indonesia. Mereka berusaha menggali seluruh informasi-informasi yang didapat dari karya-karya at-Tarmasi. At-Tarmasi (w. 1920 M) meninggal pada 1 Rajab 1338 H bertepatan tanggal 20 Mei 1920 M. Ia dikuburkan di pemakaman keluarga Syatha Makkah. Di dalam salah satu karyanya tertuang harapan at-Tarmasi, yakni mengharap kepada Allah Swt. agar kelak wafatnya di Makkah dalam kondisi husnul khatimah dan dimakamkan di Makkah juga. ${ }^{18}$

\section{Struktur Sosial Masyarakat Jawa Timur dan Peran at-Tarmasi (w. 1920 M) bagi Pesantren di Jawa Timur}

Pembahasan mengenai pengaruh pemikiran at-Tarmasi (w. 1920 M) tidak terlepas dari setting atau kondisi sosial yang mengelilingi kehidupan at-Tarmasi. Beliau lahir dan besar di lingkungan masyarakat Jawa Timur, sehingga penting untuk menelaah kondisi sosial masyarakat Jawa timur yang saat itu didominasi oleh kaum santri. Hal ini sesuai dengan pandangan Redcliffe Brown tentang

${ }^{16}$ Ibid, h. 80

${ }^{17}$ Puthut Prastyo, Analisis Kitab al-Minhatul Khairiyyah Karya Syaikh Muhammad Mahfudz Al-Tarmasi dan Kontribusinya Terhadap Pengembangan Standar Kompetensi Lulusan Pondok Pesantren Tremas Arjosari Pacitan, (Ponorogo: Skripsi IAIN Ponorogo, 2016), h. 99-103

${ }^{18}$ Muhajirin, Kebangkitan Hadits ..., h. 63-64 
struktur sosial. Baginya, struktur sosial adalah pengaturan yang dilakukan secara terus menerus atas orang-orang dalam kaitan hubungan yang ditentukan atau dikendalikan oleh institusi, yakni norma atau pola prilaku yang dimapankan secara sosial. ${ }^{19}$

Secara umum, kondisi sosial masyarakat Jawa Timur Abad 18-19 M, seperti yang telah diketahui, tidak terlepas dari kondisi Indonesia yang mengalami penjajahanan. Sejak abad $18 \mathrm{M}$ pemerintah kolonial mengubah cara eksploitasi dari cara lama yang konservatif dengan memusatkan pada perdagangan yang dikelola VOC menjadi eksploitasi yang dikelola pemerintah maupun swasta. Eksploitasi yang terakhir dipusatkan pada pemanfaatan tanah dan tenaga kerja. Pada masa itu VOC berada pada puncak kekuasaannya sehingga sedikit-banyak memberikan pengaruh pada kondisi sosial masyarakat Nusantara saat itu. VOC hendak memecah belah umat Islam dengan membaginya ke dalam pelbagai golongan dan status sosial.

Pembedaan ini sangat efektif untuk memecah persatuan umat Islam. Terlebih ketika Clifford Geertz, dalam salah satu bukunya, membagi struktur sosial masyarakat Jawa Timur menjadi tiga golongan, yaitu Abangan, Santri dan Priyayi. ${ }^{20}$ Di sana Geertz berkelah bahwa pembagian tersebut merupakan pembagian yang dibuat oleh orang-orang Jawa sendiri, padahal ini justru membawa dampak yang tajam bagi keberlangsungan umat Islam di Jawa Timur. Baik Abangan, santri maupun priyayi didefinisikan secara berbeda-beda.

Pembagian tersebut justru membuat masyarakat Jawa Timur terkooptasi dalam berbagai strata sosial. Ini bagian dari Devide Et Impera yang dilancarkan penjajah. Dari pembedaan stratifikasi sosial, banyak umat Islam, khususnya yang Abangan, yang dianggap oleh Gertz sebagai orang yang sangat jauh dari sumbersumber agama Islam. Mereka adalah orang-orang yang masih membangun kekuatan dari hal-hal yang supra natural, mistis dan sinkretis. Persatuan di kalangan kaum Abangan dibangun berdasarkan atas kekuatan alam tersebut. Karena itu, bagi pemerintah kolonial, kondisi itu sangat menguntungkan bagi mereka yang sudah membangun kekuatan berdasarkan strategi empiris. Kaum Abangan dijauhkan dari sumber-sumber agama mereka yang sebenarnya bisa menjadi sumber kekuatan tersendiri bagi kaum Muslim Abangan.

${ }^{19}$ Kaplan dan Manner, Teori Budaya (Yogyakarta: Pustaka Belajar, 2000), h. 139

${ }^{20}$ Bima Widiatiaga, Resume: abangan, santri, priyayi dalam masyarakat jawa, karya Clifford Geertz (Jakarta: Dunia Pustaka Jaya, 1981), h. 
Millatī, Journal of Islamic Studies and Humanities, Vol. 3, No. 2, Des. 2018: 261-275

Selain itu, kaum santri hanya diperkenalkan ilmu-ilmu agama yang terfokus pada kajian fiqih dan tasawuf. Hal ini dilakukan untuk menjauhkan kaum Santri untuk mengakses sumber-sumber utama Ilmu agama. Ilmu agama sendiri menjadi kekuatan tersendiri bagi kekompakan dan persatuan santri. Dan hanya kelompok priyayi lah yang memiliki keistimewaan sehingga mereka sangat dipertimbangkan oleh pemerintah kolonial. At-Tarmasi (w. 1920 M) menyadari hal ini. Ia mulai mengenalkan hadis kepada kaum santri. Materi hadis berdiri sendiri dan dijadikan sebagai kurikulum pesantren. Sejak tahun 1900 M., hadis resmi menjadi kurikulum di berbagai lembaga pendidikan di Jawa Timur. ${ }^{21}$ Usahanya kemudian diteruskan oleh muridnya, Hasyim Asy'ari, melalui pondok Hadisnya di Tebuireng, Jombang, Jawa Timur.

\section{Mengenal Kitab Hadis Arba'in At-Tarmasi}

Upaya revitalisasi ajaran Nabi Muhammad Saw. (w. 11 H/632 M) di Indonesia sudah berlangsung sejak paruh kedua abad ke-17, seiring dengan masuknya gagasan pembaharuan (modernisasi) yang menekankan kembali pada al-Qur'an dan hadis sebagai sumber ajaran Islam. Para ulama mengkaji hadis dari inspirasi dan wawasan mengenai cara memimpin masyarakat muslim menuju rekonstruksi sosial moral. ${ }^{22}$ At-Tarmasi (w. 1920 M) mengambil bagian dalam hal ini. Melalui dua karyanya, Manhāj dzaw al-nazar bi syarh manz\umah 'ilm al-atsār di bidang ilmu hadis dan al-Minhah al-Khairiyah fi Arba'in Haditsan min Ahäditsu Khair al-Bariyah di bidang hadis, at-Tarmasi (w. 1920 M) mengenalkan hadis arba'in kepada masyarakat pesantren.

Dalam konteks ini, penulis akan memaparkan karyanya yang berjudul al-Minhahah al-Khairiyah fi Arba`in Haditsan min Ahäditsu Khair al-Bariyah saja. Kitab ini dikenal dengan nama Arba'in at-tarmasi. Kitab ini memuat 40 hadis Nabi Muhammad saw. ${ }^{23}$ Karya-karya at-Tarmasi, termasuk karya ini, mulai dikenal dalam dunia akademik pada tahun 2000-an, yakni setelah kajian Islam MelayuNusantara dikumandangkan. Selain itu juga dikarenakan akan keberadaannya yang masih sulit ditemukan dan belum mendapat perhatian khusus, kecuali dari

${ }^{21}$ Muhammad Rikza Muqtada, "Independensi Keilmuan Hadis K.H. Mahfuzh alTarmasi: Jaringan Pemikiran, Pesantren dan Kolonialisme”, dalam Nur Said (ed), Santri Membaca Zaman; Percikan Pemikiran Kaum Pesantren (Kudus: Santrimenara Pustaka, 2016) h. 30

${ }^{22}$ Muhajirin, Kebangkitan Hadits ..., h. 47

${ }^{23}$ Muhajirin, Muhammad Mahfudz at-Tarmasi..., h. 76 
keluarga Tremas, dan setelah itu dari Kementrian Agama Republik Indonesia. ${ }^{24}$

Tidak ada informasi jelas dari sumber sejarah Nusantara tentang alasan penulisan karya ini. Setidaknya pernyataan Maimun Zubair, Kiyai kharismatik di Sarang Rembang, membantu untuk mengetahui alasan mengapa at-Tarmasi (w. 1920 M) menulis kitab al-Minhah al-Khairiyah ini. Sebelum at-Tarmasi (w. 1920 M) sudah banyak ulama yang mengumpulkan kemudian membukukan 40 hadis nabawi. Alasannya adalah mengamalkan hadis Nabi Muhammad Saw. (w. $11 \mathrm{H} / 632 \mathrm{M}$ ) tentang keunggulan bagi pengumpul 40 hadis Nabi Saw., sebagai berikut:

$$
\text { من حفظ علي أمتي أربعين حدثنا من أمر دينها بعثه الله يوم القيامه في زمرة الفقهاء والعلماء }
$$

"Barang siapa yang menjaga 40 hadis tentang urusan dunia, maka Allah menempatkan di akhirat kelak bersama para ulama dan fuqaha"

Juga riwayat:

من حفظ علي أمتي أربعين حدثنا من أمر دينها قيل لها دخل من أي ابواب الجنة شئت

"Barang siapa yang menjaga 40 hadis tentang urusan dunia, masuklah kesyurga dari pintu mana yang engkau sukai" 25

Lebih lanjut Maimun Zubair mengutarakan argumentasi at-Tarmasi (w. 1920 M) dalam pengumpulan 40 hadis dengan mengutip satu riwayat shahih:

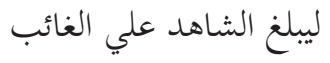

"hendaklah ada di antara kamu mengabarkan/memberitahukan kepada mereka yang tidak hadir" 26

Selain itu at-Tarmasi (w. 1920 M) juga berpegang kepada perkataan ulama sebelumnya yang menyatakan bahwa "barang siapa yang mengumpulkan 40 hadis berkenaan dengan agama, furu', jihad, adab dan khutb kesemuanya merupakan perbuatan baik".27 Hadis hadis di atas lah alasan yang mendasari at-Tarmasi

${ }^{24}$ Muhajirin, At-Tarmasi: Icon Baru Ulama Hadits..., h.315

${ }^{25}$ Hadis ini dijadikan KH. Maimun sebagai penjelasan akan tujuan at-Tarmasi dalam mengarang 40 hadis Nabi. At-Tarmasi, Al-Minhah al-Khairiyyah fi Arbain Haditsan min Ahadits Khair al-Bariyah, (Jakarta: Departemen Agama Republik Indonesia, 2008), h. pengantar

${ }^{26}$ Al-Tarmasi, al-Khil'ah al-Fiqriyyah..., h. 5

${ }^{27}$ Muhajirin, Kebangkitan Hadits ..., h. 108 
Millatī, Journal of Islamic Studies and Humanities, Vol. 3, No. 2, Des. 2018: 261-275

(w. 1920 M) terlibat dalam mengumpulkan dan membukukan ke 40 hadis tersebut.28

At-Tarmasi (w. 1920 M) menulis karya itu sewaktu masih belajar di H aramain. Ia menyelesaikan penulisan karyanya itu pada hari Ahad, tanggal 16 Ramadhan 1313 H. Selain itu, dijelaskan pula bahwa kitab ini (ketika dicetak ulang) dilengkapi harakah oleh Abdullah Zaini ibn Azir al-Jathawi, guna mempermudah para pelajar, sekaligus meminimalisir kesalahan dalam membaca dan memahaminya. ${ }^{29}$

\section{Sistematika Penulisan Kitab Hadis Arba'in At-Tarmasi}

Ke 40 hadis yang termuat dalam kitab Arbain at-Tarmasi tidak sama dengan hadis dalam kitab Arba' in Nawawi dan juga kitab Arba' in lainnya, ${ }^{30}$ kendati tema yang dipilih oleh masing-masing penulis berbeda satu sama lain. Dalam kitab Arba'in at-Tarmasi memuat 40 hadis dengan berbagai tema yang diambil dari beberapa kita hadis yang masyhur. Ulama Nusantara ini mulai mengakomodir seluruh kitab hadis kutub al-sittah, dengan cara mengambil setiap hadis pertama dan terakhir dari keenam kitab masyhur tersebut. Dan hal ini belum pernah dilakukan oleh para penulis kitab Arba'in yang telah ada sebelumnya. ${ }^{31}$

Dalam penulisannya, at-Tarmasi (w. 1920 M) secara jelas menuliskan semacam tema atau judul sebelum menuliskan matan hadisnya. Misalnya alHadits al-Tsani Awwalu Shahih al-Bukhari atau al-Hadits al-Tsani Awwalu Shahih al-Muslim dan seterusnya. Demikian pula ketika ia merujuk pada kitab lainnya, misalnya disebutkan sebagai judul al-Hadits al-Tsani Awwalu min Tsulatsiyyat al-Bukhari. Dari kesemuanya itu terkumpul 40 hadis nabi Muhammad Saw. ${ }^{32}$

Sistematika penulisan kitab hadis Arba'in at-Tarmasi memiliki keunikan tersendiri dari pada kitab-kitab hadis lainnya. Sejumlah 40 hadis yang termaktub di dalamnya diklaim oleh at-Tarmasi memiliki status hadis musalsal, yakni memiliki ketersambungan perawi hadis dengan disertai metode penyampaian yang sama dengan guru-gurunya. Hadis-hadis musalsal tersebut diambilkan dari pelbagai kitab kompilasi hadis yang terkenal (masyhur). at-Tarmasi (w. 1920 M) berusaha untuk mengakomodir seluruh kitab hadis yang tergolong kutub al-sittah.

\footnotetext{
${ }^{28}$ Muhajirin, Muhammad Mahfudz at-Tarmasi..., h. 83

${ }^{29}$ Muhajirin, At-Tarmasi: Icon Baru Ulama Hadits..., h.318

${ }^{30}$ Muhajirin, Muhammad Mahfudz at-Tarmasi..., h. 76

${ }^{31}$ Muhajirin, At-Tarmasi: Icon Baru Ulama Hadits..., h.315

${ }^{32}$ Muhajirin, Muhammad Mahfudz at-Tarmasi..., h. 77
} 
Ia menghimpun dengan cara mengambil setiap hadis pertama dan hadis yang terakhir dari keenam kitab tersebut secara berurutan. Untuk melengkapi hadis menjadi 40, at-Tarmasi (w. 1920 M) mengambilnya dari Tsulasiyat al-Bukhari, sebagai representasi dari kitab hadis yang memiliki keakurasian dan ketelitian paling tinggi.

\section{Pembacaan atas Tema-tema Hadis Arba'in At-Tarmasi}

Dari uraian 40 hadis di atas, penulis melakukan pengujian antara hadis satu dengan hadis lainnya. Bahwa, at-Tarmasi (w. 1920 M) memilih hadis- hadis musalsal untuk diambilnya. Hadis musalsal adalah hadis yang secara berturutturut sanad-nya sama dalam satu sifat atau dalam satu keadaan dan atau dalam satu periwayatan. ${ }^{33}$ Kemudian, at-Tarmasi (w. 1920 M) tidak melakukan kembali kritik sanad dan matan terhadap hadis- hadis yang diambil. Karena, menurut penulis at-Tarmasi menilai baik terhadap kitab-kitab yang diambil (kutubu sittah).

Hadis- hadis yang dipilih oleh at-Tarmasi memiliki keterkaitan antara satu dengan yang lainnya, sehingga di sana terdapat relasi antar hadis yang dapat membentuk satu wacana dalam konteks keislaman Indonesia. Untuk memudahkan maka perlu upaya pengklasifikasian atas tema-tema hadis Arba' in ke dalam tema-tema besar. Dalam proses pengklasifikasian didapatkan beberapa tema pokok hadis Arba'in at-Tarmasi yang meliputi: aq̄idah (teologi), ubūdiyah (peribadatan), mu'āmalah (relasi sosial) dan siyāsah (startegi politik). Keempat hal itulah yang menjadi pilar-pilar penting dalam realitas kehidupan masyarakat Muslim di Indonesia. Tanpa keempan pilar tersebut umat Islam Indonesia akan mengalami kelemahan. Karena itulah at-Tarmasi (w. 1920 M) mengingatkan akan pentingnya mengkaji pilar-pilar tersebut langsung dari sumbernya.

Selain empat hal tersebut di atas, karya at-Tarmasi (w. 1920 M) memiliki keunikan tersendiri. Hadis yang dipilih at-Tarmasi pertama kali bukanlah hadishadis yang juga ditulis pertama kali oleh ahli-ahli hadis lain. At-Tarmasi (w. 1920 M) memilih hadis tentang rahmah (kasih sayang) untuk ditulis pertama kali dalam karyanya. Dalam teori wacana, setiap teks memiliki ideologi tersendiri, sehingga pemilihan atas teks-teks tertentu mengandung ideologi atau misi-misi tertentu pula. Karena itu, penulis berpandangan bahwa pemilihan pertama kali hadis tentang rahmah oleh at-Tarmasi (w. 1920 M) memiliki misi untuk memberikan strategi, khususnya bagi santri, untuk mencetak pribadi yang mengedepankan

\footnotetext{
${ }^{33}$ Abdul Majid Khon, Ulumul Hadis (Jakarta: Amzah, 2010), h. 237
} 
Millatī, Journal of Islamic Studies and Humanities, Vol. 3, No. 2, Des. 2018: 261-275

kasih sayang atas rasa kemanusiaan. Kasih sayang dalam kemanusiaan merupakan hal penting dalam kehidupan manusia. Karenanya segala bentuk perilaku yang menjauhkan diri dari rasa kasih sayang, seperti penindasan, eksploitasi, perbudakan dan lainnya harus dilawan.

Pemilihan tersebut justru menjadi strategi politik bagi at-Tarmasi (w. 1920 M) dalam melawan penjajahan Belanda yang dirasa sangat tidak berperikemanusiaan. Melalui teks hadis tersebut santri diperkenalkan dengan rasa kasih sayang serta peduli akan kemanusiaan. Santri harus mengenal betapa pentingnya rasa kasih sayang terhadap sesama manusia, sehingga kekejaman yang mengancam rasa kemanusiaan harus dilawan dengan niat yang ikhlas. Karena itulah, at-Tarmasi (w. 1920 M) kemudian menyusulnya dengan hadis kedua dengan niat. Kaum santri harus niat bersungguh-sungguh dalam melawan penjajahan semata-mata hanya karena Allah Swt.

Lebih lanjut, hadis-hadis yang dipilih at-Tarmasi (w. 1920 M) mayoritas berbicara tentang perang. Bahkan dalam satu hadisnya secara spesifik menyebutkan perang Khaibar. Karena konteks kebangsaan Indonesia adalah serupa dengan kondisi perang Khaibar, di mana umat Islam sedang menjalankan perlawanan atas imperialism dan kolonialisme penjajah Belanda dengan senjata seadanya dan terbatas. Dengan segala keterbatasan itu, santri harus tetap bersemangat dalam berjuang melawan penjajahan. Maka dari itu, at-Tarmasi (w. 1920 M) memberikan semangat melalui ibrah dari peristiwa perang tersebut.

\section{Kontribusi Hadis Arba'in At-Tarmasi dalam Konteks Keindonesiaan}

Sejak abad 12 hingga $16 \mathrm{M}$ dunia Islam sedang berada dalam kekuasaan kolonial yang mengakibatkan umat Islam berada dalam kekuasaan kolonial yang mengakibatkan umat Islam berada dalam dunia intelektual yang nyaris terjun bebas dan redup. Di sisi lain, materi tasawuf dengan berbagai metodologinya yang dikenal sejak abad ke-3 menjadikan umat Islam terlena dan ternina bobokan dengan ajaran-ajaran yang terselimuti kemurniannya dai ajaran Islam yang bersumber pada al-Qur'an dan al-Hadis, akibatnya diracuni bid'ah dan taklid, kondisi keberagamaan seperti ini juga sangat terasa di Nusantara.

Fenomena dan kondisi ini membuat para ulama pada masa itu bangkit menyeru umat Islam agar kembali kepada sumber hukum Islam, yakni al-Qur'an dan al-Hadis. At-Tarmasi (w. 1920 M) merupakan salah satu ulama tersebut yang memberikan kontribusinya melalui karya-karya yang ditulisnya. Dengan 
karyanya at-Tarmasi bisa memberikan sumbangan pemahaman tentang agama Islam bagi masyarakat Nusantara, menerangkan redupnya dunia intelektual Islam pada masa itu. ${ }^{34}$

Kepedulian at-Tarmasi (w. 1920 M) bagi masyarakat tercermin dalam tema-tema hadisnya. Sebagaimana telah disebutkan di atas adanya empat pilar penting bagi keberlangsungan hidup umat Islam Indonesia. Di antaranya adalah tentang ubūdiyah, mu'āmalah dan siyāsah. Sebagaimana telah diketahui, ubūdiyah merupakan hal penting dalam perjalanan hidup setiap individu. Karena itu, at-Tarmasi (w. 1920 M) sengaja memasukkan banyak hadis mengenai tata cara beribadah, mulai dari bersuci, shalat, perawatan jenazah dan lainnya. Tujuan utamanya adalah agar masyarakat, terlebih kaum santri, berhati-hati dalam urusan ibadah supaya bisa diterimaa oleh Allah Swt.

Ibadah sendiri berasal dari bahasa Arab, yaitu abida ya'budu 'abdan 'ibādatan yang berarti taat, tunduk, patuh dan merendahkan diri. Semua pengertian itu mempunyai makna yang berdekatan. Sesorang yang tunduk, patuh, dan merendahkan diri dihadapan yang disembah disebut 'abid (yang beribadah). Kemudian dalam terminologinya, ibadah diartikan semua yang mencakup segala perbuatan yang disukai dan diridhai oleh Allah Swt., baik berupa perkataan maupun perbuatan, baik terang-terangan maupun tersembunyi. Semuanya dalam rangka mengagungkan Allah Swt. serta mengharapkan pahalaNya. Misalnya, shalat terdiri dari hal-hal yang berhubungan dengan anggota badan seperti rukuk dan sujud, juga hal-hal yang berhubungan dengan lidah seperti dzikir dan hati seperti niat.

Selain mengenai ubudiyah, at-Tarmasi (w. 1920 M) juga mengambil mu'āmalah sebagai tema besar dalam kitabnya. Mu'āmalah dalam arti luas adalah aturan-aturan yang mengatur hubungan manusia dengan manusia dalam hubungan tertentu. Dalam kitabnya at-Tarmasi (w. 1920 M) banyak sekali menyinggung mengenai muamalah, merupakan strategi at-Tarmasi (w. 1920 M) dalam mendoktrin masyarakat khusunya kaum santri dalam berperilaku supaya terlahir jiwa-jiwa yang peduli atas kemanusiaan. Etika menjadi sasaran utama at-Tarmasi (w. 1920 M) dengan tujuan untuk membina masyarakat yang berakhlaqul karimah.

Selanjutnya adalah siyāsah. Siyāsah yang dibahas at-Tarmasi (w. 1920 M) dalam kitabnya tersebut banyak yang membahas tentang peristiwa Khaibar, di mana peristiwa Khaibar tersebut digambarkan dengan kondisi Nusantara saat

\footnotetext{
${ }^{34}$ Muhajirin, Kebangkitan Hadits ..., h. 143-145
} 
Millatī, Journal of Islamic Studies and Humanities, Vol. 3, No. 2, Des. 2018: 261-275

itu dalam tekanan penjajah. at-Tarmasi (w. 1920 M) dalam menghimpun hadishadis tersebut mempunyai maksud untuk menumbuhkan semangat berjuang masyarakat Nusantara terutama kalangan para santri yang menjadi sasaran pertama dalam penyampaian hadis tersebut.

\section{Kesimpulan}

Dari pembahasan di atas dapat diketahui bahwa, penulisan hadis Arba'in atTarmasi dilatarbelakangi oleh kondisi masyarakat Muslim Indonesia yang semakin dijauhkan dari sumber ajaran Islam oleh penjajah Belanda. Pemerintah Belanda hanya memperbolehkan fiqih dan tasawuf sebagai kurikulum dalam pesantren. Karena itu, at-Tarmasi berusaha untuk mengenalkan hadis bagi masyarakat Muslim Indonesia dengan memasukkan hadis sebagai kurikulum pesantren. Di samping itu, at-Tarmasi (w. 1920 M) berusaha untuk mengamalkan isi hadis Nabi Saw. yang berkaiatan dengan keunggulan bagi pengumpul 40 hadis Nabi Muhammad Saw.

Selanjutnya, sistematika penulisan kitab hadis Arba'in at-Tarmasi diklaim oleh penulisanya memiliki status hadis musalsal yang diambilkan dari pelbagai kitab kompilasi hadis yang terkenal, yakni kutub al-sittah. Ia menghimpun dengan cara mengambil setiap hadis pertama dan hadis yang terakhir dari keenam kitab tersebut secara berurutan. Untuk melengkapi hadis menjadi 40, at-Tarmasi (w. 1920 M) mengambilnya dari Tsulasiyat al-Bukhari sebagai representasi dari kitab hadis yang memiliki keakurasian dan ketelitian paling tinggi.

Terakhir, secara umum tema-tema hadis dalam karya Arba'in at-Tarmasi terdiri dari empat tema utama, yaitu aquidah (teologi), ubüdiyah (peribadatan), mu'āmalah (relasi sosial) dan siyāsah (startegi politik). Keempat hal inilah yang menjadi pilar-pilar penting dalam realitas kehidupan masyarakat Muslim di Indonesia. Tanpa keempat pilar tersebut umat Islam Indonesia akan mengalami kelemahan. Karena itulah at-Tarmasi (w. 1920 M) mengingatkan akan pentingnya mengkaji pilar-pilar tersebut langsung dari sumbernya secara musalsal.

\section{Referensi}

Aizid, Rizem. Biografi Ulama Nusantara: Disertai Pemikiran dan Pengaruh Mereka. Yogyakarta: Diva Press, 2016.

At-Tarmasi, Mahfuzh. al-Khilah al-Fikriyah Syarah al-Minhah al-Khairiyah. Jakarta, Departemen Agama Republik Indonesia, 2008. 
At-Tarmasi, Mahfuzh. Al-Minhah al-Khairiyyah fi Arbain Haditsan min Ahadits Khair al-Bariyah. Jakarta: Departemen Agama Republik Indonesia. 2008 Fathurrahman, Oman. "Ulah Malaysia dan Ketidakpedulian Kita”. Dalam Agung Danarto. Kajian Hadis di Indonesia Tahun 1900-1945 (Telaah terhadap Pemikiran Beberapa Ulama tentang Hadis). Yogyakarta: Proyek Perguruan Tinggi Agama Islam, IAIN Sunan Kalijaga, 2000.

Kaplan dan Manner, Teori Budaya. Yogyakarta: Pustaka Belajar, 2000.

Khon, Abdul Majid. Ulumul Hadis. Jakarta: Amzah, 2010.

Muhajirin, Muhammad Mahfudz at-Tarmasi (1868-1919): Ulama Hadits Nusantara Pertama. Yogyakarta: Idea Press, 2016.

Muhajirin. "At-Tarmasi: Icon Baru Ulama Hadits Arba'in Di Indonesia”. Jurnal ASILHA International Conference. tt.

Muhajirin. Kebangkitan Hadits Di Nusantara. Yogyakarta: Idea Press, 2016.

Muqtada, Muhammad Rikza. "Independensi Keilmuan Hadis K.H. Mahfuzh at-tarmasi: Jaringan Pemikiran, Pesantren dan Kolonialisme”. dalam Nur Said (ed). Santri Membaca Zaman; Percikan Pemikiran Kaum Pesantren. Kudus: Santrimenara Pustaka, 2016.

Prastyo, Puthut. Analisis Kitab al-Minhatul Khairiyyah Karya Syaikh Muhammad Mahfudz At-tarmasi dan Kontribusinya Terhadap Pengembangan Standar Kompetensi Lulusan Pondok Pesantren Tremas Arjosari Pacitan. Ponorogo: Skripsi IAIN Ponorogo, 2016.

Tasrif, Muh. dkk. "Rekontekstualisasi Al-Hadits di Indonesia". Jurnal Istiqra. volume 03, nomor 01, 2004.

Widiatiaga, Bima. Resume: abangan, santri, priyayi dalam masyarakat jawa, karya Clifford Geertz. Jakarta: Dunia Pustaka Jaya, 1981. 
